\title{
Restoration of PPP2CA expression reverses epithelial-to-mesenchymal transition and suppresses prostate tumour growth and metastasis in an orthotopic mouse model
}

\author{
A Bhardwaj ${ }^{1}$, S Singh ${ }^{1}$, S K Srivastava ${ }^{1}$, S Arora ${ }^{1}$, S J Hyde ${ }^{1}$, J Andrews ${ }^{1}$, W E Grizzle ${ }^{2}$ and A P Singh ${ }^{* 1,3}$ \\ ${ }^{1}$ Department of Oncologic Sciences, Mitchell Cancer Institute, University of South Alabama, Mobile, AL 36604, USA; ${ }^{2}$ Department \\ of Pathology, University of Alabama at Birmingham, Birmingham, AL 35294, USA and ${ }^{3}$ Department of Biochemistry and Molecular \\ Biology, College of Medicine, University of South Alabama, Mobile, AL 36688, USA
}

Background: Emergence of castration-resistance in prostate cancer (PCa) is invariably associated with aggressive and metastatic disease. Previously, we reported promotion of castration-resistance upon downregulation of PPP2CA (encoding catalytic subunit of protein phosphatase 2A (PP2A), $\alpha$-isoform); however, its role in PCa growth and metastasis remained undetermined.

Methods: PPP2CA was overexpressed/silenced in PCa cells by stable transfection. Gene expression was examined by reverse transcription polymerase chain reaction, immunoblot and immunofluorescence analyses, and transcriptional activity measured by luciferase-based promoter-reporter assay. Effect on PCa phenotype was studied in vitro and in orthotopic mouse model, and immunohistochemical/histological analyses performed to assess proliferation/apoptosis and confirm metastatic lesions.

Results: An inverse association of PPP2CA expression was observed with epithelial-to-mesenchymal transition (EMT) and aggressive PCa phenotype. PPP2CA restoration resulted in decreased nuclear accumulation and transcriptional activity of $\beta$-catenin/NF- $\kappa \mathrm{B}$, and restitution of their activity abrogated PPP2CA-induced EMT reversal and suppression of PCa invasiveness. Akt mediated PPP2CA loss-induced nuclear accumulation of $\beta$-catenin/NF- $k \mathrm{~B}$ through inactivation of Gsk3- $\beta$ and $I_{\kappa} \mathrm{B}-\alpha$, respectively. Animal studies revealed a suppressive effect of PPP2CA expression on PCa growth and metastasis.

Conclusions: Our findings suggest that PPP2CA downregulation serves as a molecular link between gain of castration-resistance and aggressive PCa phenotype, and its restoration could be an effective preventive/therapeutic approach against the advanced disease.

Prostate cancer $(\mathrm{PCa})$ is the most commonly diagnosed noncutaneous malignancy and second leading cause of cancer-related death in American men. The American Cancer Society estimates that in 2014, there will be 233000 new diagnoses of PCa, and nearly 29480 patients will die of this disease (Siegel et al, 2014). Owing to widespread screening, most patients are now diagnosed with localised prostate tumours; however, a significant proportion still continues to present with locally advanced or metastatic disease (Cooperberg et al, 2005). At the present time, there is no effective cure for the advanced disease and androgen deprivation therapy (ADT) remains the principal treatment option (Feldman and Feldman, 2001). Unfortunately, most PCa patients treated with $\mathrm{ADT}$ eventually acquire castration-resistant phenotype, a form, which is highly aggressive and unresponsive to other therapies (Joly and Tannock, 2004; Sridhar et al, 2013). Therefore, characterisation of molecular targets facilitating PCa progression

\section{*Correspondence: Dr AP Singh; E-mail: asingh@health.southalabama.edu}

Received 17 January 2013; revised 17 February 2014; accepted 24 February 2014; published online 18 March 2014 
and metastasis, and deciphering their mechanisms of action is critically important to develop effective treatment approaches.

Protein phosphatase 2A (PP2A) is the most abundant serine/ threonine phosphatase in mammals and has important roles in several biological processes (Mumby, 2007; Perrotti and Neviani, 2013). It consists of a common heteromeric core enzyme, which is composed of a catalytic subunit and a constant regulatory subunit that associates with a variety of regulatory subunits (Janssens and Goris, 2001). Previously, we identified that PPP2CA, which encodes the alpha isoform of the catalytic subunit $(\mathrm{PP} 2 \mathrm{Ac} \alpha)$, is one of the downregulated genes in castration-resistant PCa cells (Singh et al, 2008). More importantly, an inverse correlation of PPP2CA expression with increasing Gleason grades and tumour stage was also observed (Singh et al, 2008). In other recent studies, we have observed that PPP2CA downregulation confers androgen depletion resistance to PCa cells (Bhardwaj et al, 2011). The data revealed that the loss of $\mathrm{PP} 2 \mathrm{~A}$-mediated checkpoints led to activation of Akt and ERK, and partially sustained androgen receptor signalling under steroid-deprived condition (Bhardwaj et al, 2011). Interestingly, studies from other groups have reported loss and functional significance of additional PP2A subunits (PP2A-C $\beta, \quad \mathrm{PP} 2 \mathrm{~A}-\mathrm{B} \gamma$ and $\mathrm{PP} 2 \mathrm{~A}-\mathrm{A} \alpha)$ as well; suggesting that dysregulation of PP2A may be a frequent occurrence in $\mathrm{PCa}$ pathogenesis (Prowatke et al, 2007; Bluemn et al, 2013; Pandey et al, 2013).

As emergence of castration-resistance in $\mathrm{PCa}$ is invariably associated with highly aggressive and metastatic disease (Jennbacken et al, 2006; Srivastava et al, 2012), it appears that there may be a common molecular thread for these distinct phenotypes. If such an association is characterised at the molecular level, it can have significant impact on the management of PCa. Therefore, this study was aimed at determining the role of $P P P 2 C A$ in PCa progression and metastasis. We developed 'paired' PCa cell lines, in which $P P P 2 C A$ expression is either stably 'restored' or 'silenced' through genetic engineering approaches. Using these cell lines, we demonstrate that PPP2CA downregulation promotes migration and invasion of PCa cells. Furthermore, our data show that $P P P 2 C A$ expression is associated with loss of mesenchymal and gain of epithelial characteristics. Mechanistically, we find important roles of Akt-driven $\beta$-catenin and NF- $\kappa \mathrm{B}$ activation in PPP2CA downregulation-induced epithelial-to-mesenchymal transition (EMT) and invasiveness of PCa cells. Finally, our data demonstrate that restoration of $P P P 2 C A$ expression attenuates PCa growth and metastasis in an orthotopic mouse model. Thus, our findings suggest that PPP2CA downregulation may be a common link between castration-resistance and aggressive tumour phenotypes, and its targeting may be useful in stalling PCa progression as well as in the treatment of the advanced disease.

\section{MATERIALS AND METHODS}

Cell lines, antibodies and plasmids. All cell lines (LNCaP, C4-2 and PC3) were procured, maintained and validated intermittently as described earlier (Srivastava et al, 2012). Anti-PP2Ac $\alpha$ (rabbit polyclonal) and anti-cytokeratin 18 (mouse monoclonal) antibodies were purchased from Abcam (Cambridge, MA, USA). Antibodies against ERK1/2, NF- $\kappa \mathrm{B} / \mathrm{p} 65$, Slug (rabbit monoclonal), pERK1/2, I $\kappa \mathrm{B}-\alpha$ (mouse monoclonal) and $\mathrm{p}-\mathrm{I} \kappa \mathrm{B}-\alpha$ (rabbit polyclonal) were from Cell Signaling Technology (Beverly, MA, USA). Antibodies against Akt, p-Akt and vimentin (rabbit monoclonal) were from Epitomics (Burlingame, CA, USA). Antibodies against $\beta$-catenin, E-cadherin and $\mathrm{N}$-cadherin (all mouse monoclonal) were from BD transduction laboratories (Bedford, MA, USA). Anti- $\beta$-actin (mouse monoclonal) antibody was from Sigma-Aldrich (St Louis, MO, USA). Anti-Twist (rabbit polyclonal), anti- $\alpha$-tubulin, anti-laminin (mouse monoclonal), and all HRP-, FITC- and TRITC-conjugated secondary antibodies were from Santa Cruz Biotechnology (Santa Cruz, CA, USA). PPP2CAshort hairpin RNA expression plasmid (PPP2CA-shRNA-pGFP$\mathrm{V}$-RS), non-targeted control plasmid (NT-shRNA-pGFP-V-RS), $P P P 2 C A$ overexpression (PPP2CA-pCMV6) and empty vector (pCMV6) constructs were purchased from Origene (Rockville, MD, USA). pGL4.32 (luc2P/NF-B-RE/Hygro) and pRL-TK plasmids were from Promega (Madison, WI, USA). TOPflash or FOPflash reporter plasmids were kindly provided by Dr R Samant, UAB, Birmingham, AL, USA. pcDNA3- $\beta$-catenin S33Y (plasmid number 19286), pCMV-IKK $\beta$ S177E S181E (plasmid number 11105) and pcDNA3-HA PKB T308D S473D (plasmid number 14751) were from E Fearon, A Rao and J Woodgett Laboratories, respectively, and procured through Addgene (Cambridge, MA, USA).

Transfections and treatments. For overexpression (in PC3 and C4-2) and knockdown (in LNCaP) of PPP2CA, cells were transfected with $P P P 2 C A$-overexpressing or shRNA plasmids, respectively, along with their control plasmids (empty vector for overexpression and non-targeted control vector for shRNA) using FuGENE (Roche, Mannheim, Germany) as a transfection reagent following the manufacturer's instructions. Stable pooled population of transfected cells were obtained using selective antibiotic containing media $\left(\mathrm{G} 418,200 \mu \mathrm{g} \mathrm{ml}^{-1}\right.$ or puromycin $2 \mu \mathrm{g} \mathrm{ml}^{-1}$ ). Following selection, cells were expanded and examined for stable PPP2CA overexpression or silencing. Cells were transiently transfected with constitutively active mutant plasmids of IKK $\beta$, $\beta$-catenin and $\mathrm{PKB}$, or with respective empty vector plasmids using FuGENE as per the manufacturer's instructions. To dissect the role of the Akt signalling pathway, cells were treated with $20 \mathrm{~mm}$ LY294002 (PI3K inhibitor; Cell Signaling Technology) for various time intervals as described in respective figure legends.

RNA isolation and reverse transcription polymerase chain reaction (RT-PCR). Total RNA was isolated from the cultured cells using RNeasy Kit (Qiagen, Gaithersburg, MD, USA). Subsequently, complementary DNA (cDNA) was synthesised using High Capacity cDNA Reverse Transcription Kit (Applied Biosystems, Carlsbad, CA, USA). Quantitative real-time PCR was performed in 96-well plates using SYBR Green Master Mix (Applied Biosystems) on an iCycler system (Bio-Rad, Hercules, CA, USA). Specific sequences of PCR primers used in this study are listed in Supplementary Table S1. The thermal conditions for real-time PCR assays were as follows: cycle $1: 95^{\circ} \mathrm{C}$ for $10 \mathrm{~min}$, cycle $2(\times 40): 95^{\circ} \mathrm{C}$ for $10 \mathrm{~s}$ and $58^{\circ} \mathrm{C}$ for $45 \mathrm{~s}$. Threshold cycle $\left(C_{T}\right)$ values for each were separately normalised against $C_{T}$ values for GAPDH, and a relative fold change in expression with respect to a reference sample was calculated by the $2^{-\Delta \Delta \mathrm{Ct}}$ method.

PP2A activity assay. Protein phosphatase 2A activity was determined using PP2A immunoprecipitation phosphatase assay kit as described earlier by us (Bhardwaj et al, 2011).

Nuclear and cytoplasmic fractionation. The preparation of cytoplasmic and nuclear extracts was performed using the Nuclear Extract Kit (Active Motif, Carlsbad, CA, USA) as described previously by us (Arora et al, 2011).

Immunoblot analysis. Immunoblotting was performed as described earlier (Bhardwaj et al, 2011) using specific antibodies against various proteins. $\beta$-Actin, $\alpha$-tubulin and laminin were used as loading controls for total, cytoplasmic and nuclear proteins, respectively. All the primary antibodies were used at $1: 1000$ dilution except antibodies against Twist, $\alpha$-tubulin and laminin, which were used at $1: 200$ dilution. All the secondary antibodies were used at $1: 2500$ dilution. 
Immunofluorescence assay. Actin staining was performed as described previously by us (Srivastava et al, 2012). For $\beta$-catenin and NF- $\kappa \mathrm{B} / \mathrm{p} 65$ staining, cells were fixed in ice-cold methanol, washed, blocked and incubated with respective antibodies diluted in antibody diluent $(1: 50)$ for $90 \mathrm{~min}$ at room temperature followed by washing. Cells were then incubated with FITC- or TRITC-conjugated goat anti-rabbit secondary antibodies $(1: 500)$ for $60 \mathrm{~min}$. Thereafter, cells were washed, mounted with antifade Vectashield mounting medium (Vector Laboratories Inc., Burlingame, CA, USA) and observed under Nikon Eclipse TE2000-U fluorescent microscope (Nikon Instruments Inc., Melville, NY, USA).

$\mathrm{TCF} / \mathrm{LEF} / \beta$-catenin and NF- $\kappa \mathrm{B}$ transcriptional activity assays. To examine the effect of PPP2CA modulation on transcriptional activity of LEF/TCF and NF- $\kappa \mathrm{B}$, cells were transiently co-transfected with the luciferase promoter-reporter constructs (TOPflash or FOPflash, or pGL4.32 (luc2P/NF- $\kappa$ B-RE/Hygro)) and pRL-TK (control reporter plasmid containing a Renilla reniformis luciferase gene downstream of the TK promoter). After $24 \mathrm{~h}$ of transfection, total protein was harvested in reporter lysis buffer (Promega). Firefly and Renilla luciferase activities were measured using a dual-luciferase assay kit (Promega) according to the manufacturer's instructions.

Motility and invasion assays. Effects of the modulation of PPP2CA expression on the migration and invasion ability of $\mathrm{PCa}$ cells were examined using non-coated or Matrigel-coated transwell chamber by following the previously described procedure (Srivastava et al, 2012).

Orthotopic xenograft mouse tumour model. All animal experiments were performed in compliance with Institutional Animal Care and Use Committee (IACUC) guidelines. Immunodeficient male mice (4- to 6-week old; Harlan Laboratories, Prattville, AL, USA) were anaesthetised with intraperitoneal injection of ketamine $\left(100 \mathrm{mg} \mathrm{kg}^{-1}\right)$ and xylazine $\left(15 \mathrm{mg} \mathrm{kg}^{-1}\right)$. After cleaning their abdomen, a small midline incision was made to expose the prostate gland, and cells $\left(1 \times 10^{6}\right.$ suspended in $50 \mu \mathrm{l}$ of HBSS medium) were injected into the dorsal prostatic lobe. The abdominal wound was closed in two layers and animals were monitored every alternate day. At the end point (30 days postimplantation), mice were killed by $\mathrm{CO}_{2}$ asphyxiation and autopsied. Prostate tumours were resected, weighed and measured for their dimensions using Vernier Calipers. Tumour volume was calculated by the following formula: $\left(A \times B^{2}\right) / 2$, where $A$ is the larger and $B$ is the smaller of the two dimensions. To examine the metastases, distinct organs (liver, lung, bone and lumbar lymph nodes) were dissected and fixed in Bouin's solution. Numbers of visible metastatic nodules were counted (in case of liver and lung) and total mass of collected lumbar lymph nodes was recorded.

IHC and histological analyses. Immunohistochemical (IHC) analysis was performed on deparaffinised and rehydrated tissue sections from formalin-fixed, paraffin-embedded blocks of orthotopically developed prostate tumours. In brief, 5- $\mu$ m thick tumour sections were deparaffinised using EZ-Dewax (Biogenex, Fremont, CA, USA) and incubate in methanol containing 3.0\% hydrogen peroxide for $30 \mathrm{~min}$ to block endogenous peroxidase activity. Thereafter, antigen retrieval was achieved by using decloaking Chamber (Biocare Medical, Concord, CA, USA) according to the manufacturer's protocol. Later sections were blocked for $10 \mathrm{~min}$ with Background Sniper (Biocare Medical) and incubated with the following primary antibodies for $60 \mathrm{~min}$ at room temperature. Subsequently, sections were incubated at room temperature with recommended polymer and probe (Biocare Medical) according to the manufacturer's protocol. Immunoreactivity was visualised by using DAB Chromogen followed by haematoxylin counterstain. Negative control tissues were also incubated in all reagents with no primary antibody. Apoptotic cells in tumour samples were identified by using DeadEnd Fluorometric TUNEL System (Promega) according to the manufacturer's instructions. Presence of a reddish brown precipitate indicated a positive reaction. The number of proliferative and apoptotic cells were counted in ten random view fields $(\times 200$ magnification $)$ in a double-blinded manner and expressed as average number of cells per field view. Histological examination followed by haematoxylin and eosin (H\&E) staining was performed on the Bouin's solution-fixed, paraffin-embedded tissue sections of the livers, lungs, lymph nodes and bones to examine the presence of metastatic tumour nodules. In case of bone, specimens were decalcified in 10\% EDTA in PBS for 14 days at $4{ }^{\circ} \mathrm{C}$ before paraffin embedding.

Statistical analysis. All the experiments were performed at least three times, independently and all data are expressed as 'mean \pm s.d.' Wherever appropriate, the data were also subjected to unpaired two-tailed Student's $t$-test. $P<0.01$ was considered statistically significant.

\section{RESULTS}

PPP2CA expression is inversely associated with migratory and invasive potential of $\mathrm{PCa}$ cells. To investigate the role of $P P P 2 C A$ in the aggressive malignant behaviour of PCa cells, we overexpressed it in C4-2 and PC3 (low PPP2CA expressing) and silenced in LNCaP (high PPP2CA expressing) cells by stable transfection. Expression and activity of its encoded protein (PP2Ac $\alpha$ ) were assessed in stable transfectants by immunoblot and malachite green-based assays, respectively. The data demonstrate significant overexpression and enhanced activity of PP2Ac $\alpha$ in C4-2-PPP2CA and PC3-PPP2CA cells as compared with their respective controls (C4-2-Neo and PC3-Neo; Figures $1 \mathrm{~A}$ and $\mathrm{B}$ ). Similarly, PPP2CA-knockdown LNCaP cells (LNCaP-shPPP2CA) exhibit reduced expression and activity of PP2Ac $\alpha$ in comparison with its non-targeted scrambled sequence expressing control (LNCaP-NT) cells (Figures 1A and B). Furthermore, consistent with our prior observation in transient assays (Bhardwaj et al, 2011), PPP2CA-overexpressing C4-2 and PC3 cells exhibit decreased phosphorylation of Akt and ERK (PP2A substrates), while it is increased in $P P P 2 C A$-silenced $\mathrm{LNCaP}$ cells (Supplementary Figure S1).

We next examined the effect of $P P P 2 C A$ overexpression or silencing on the migration and invasive potential of $\mathrm{PCa}$ cells. Our data show that PPP2CA-overexpressing C4-2 and PC3 cells have significantly $(P<0.01)$ reduced migratory $(2.3$ - and 2.2 -fold, respectively) and invasive (2.7- and 2.8 -fold, respectively) potential as compared with their respective controls (Figure 1C). Similarly, we also observe a significant gain $(P<0.01)$ in migratory $(2.4$-fold $)$ and invasive (3.0-fold) behaviour of PPP2CA-knockdown LNCaP cells (Figure 1C). Together, these data indicate that PPP2CA suppresses aggressive behaviour of the PCa cells.

Loss of PPP2CA facilitates EMT transition in PCa cells. Several lines of evidence indicate that increased malignant potential of cancer cells is associated with their transition from epithelialto-mesenchymal phenotype, a process referred as EMT (Kang and Massague, 2004; Nauseef and Henry, 2011). Therefore, we investigated whether altered expression of PPP2CA had an impact on EMT process. For this, we first examined actin organisation in PPP2CA-overexpressing or PPP2CA-knockdown $\mathrm{PCa}$ cells considering the fact that actin-dependent membrane protrusions act as critical determinants of EMT (Shankar et al, 2010). Staining of filamentous-actin with FITC-conjugated phalloidin revealed the presence of many filopodial structures in low PPP2CA-expressing (C4-2-Neo, PC3-Neo and LNCaP-shPPP2CA) cells, while they were absent or less obvious in the high 
A

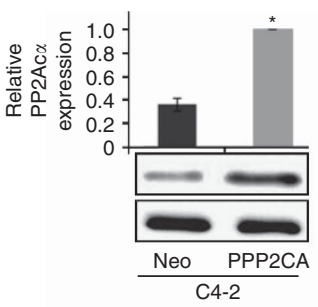

B

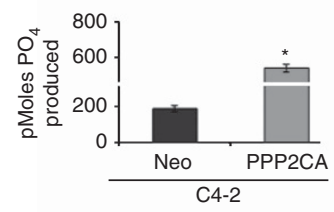

C

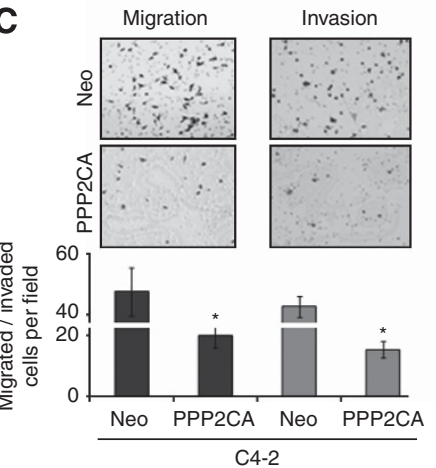

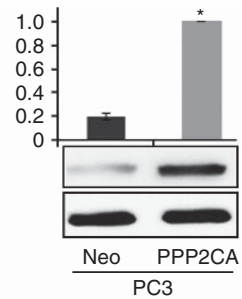
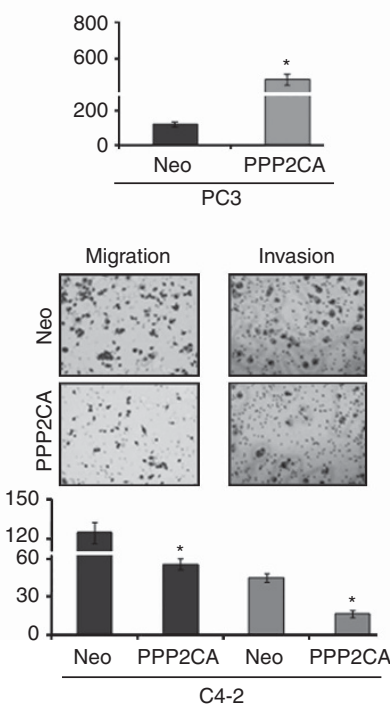
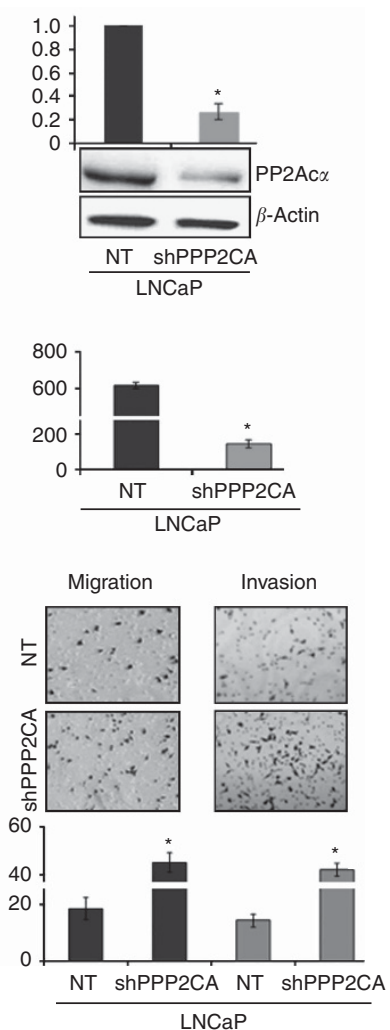

Figure 1. Overexpression of PPP2CA suppresses malignant behaviour of PCa cells. Expression (A) and activity (B) of PP2Ac $\alpha$ in stable pooled populations of PPP2CA-overexpressing (C4-2- and PC3-PPP2CA) and PPP2CA-silenced (LNCaP-shPPP2CA) PCa cells, along with their respective empty vector (-Neo) and non-targeting scrambled-shRNA (-NT) transfected control cells were examined by immunoblot analysis and malachite green-based assay, respectively. $\beta$-Actin was used as a loading control in immunoblot analysis. (C) Cells were seeded in a transwell chamber ( $8 \mu \mathrm{m}$ pore size, non-coated or Matrigel-coated) and allowed to migrate or invade overnight under chemotactic drive. After overnight incubation, the cells that did not migrate or invade through the membranes were removed and migrated/invaded cells were stained using a commercial kit. Images were taken in 10 random fields (magnification $\times 100$ ) and cell number counted. The data are presented as mean \pm s.d., $(n=3)$. ${ }^{\star} P<0.01$.

PPP2CA-expressing (C4-2-PPP2CA, PC3-PPP2CA and LNCaP$\mathrm{NT}$ ) cells (Figure 2A). To further confirm the role of PPP2CA on EMT, we examined the expression of markers associated with epithelial (E-cadherin and cytokeratin-18) and mesenchymal (N-cadherin, vimentin, Twist and Slug) phenotypes by qRT-PCR and immunoblot assays. Our data show that suppression of PPP2CA in LNCaP cells causes increased expression of mesenchymal markers, whereas those associated with epithelial phenotype are suppressed both at transcriptional (Figure $2 \mathrm{~B}$ ) and protein levels (Figure 2C). On the other hand, PPP2CA-overexpressing C4-2 and PC3 cells exhibit greater expression of epithelial and reduced expression of mesenchymal markers as compared with their respective controls (Figures $2 \mathrm{~B}$ and $\mathrm{C}$ ). Together, these findings suggest that loss of PPP2CA expression facilitates EMT in PCa cells.

Activation of $\beta$-catenin and $\mathrm{NF}-\kappa \mathrm{B}$ is involved in PPP2CA downregulation-induced EMT and aggressive behaviour of PCa cells. To explore the mechanistic basis of PPP2CA loss-induced EMT, we focused on $\beta$-catenin and NF- $\kappa \mathrm{B}$, which have earlier been shown to be aberrantly activated in PCa (Ross et al, 2004; Jaggi et al, 2005; Lessard et al, 2006), and implicated in transcriptional regulation of EMT markers (Min et al, 2008; Li et al, 2012, 2013). Our data from luciferase-based promoter-reporter assays show decreased transcriptional activity ( $>2.4$-fold) of both LEF/TCF/ $\beta$-catenin and NF- $\kappa \mathrm{B}$ in PPP2CA-overexpressing PC3 cells as compared with that in control cells (Figure 3A). Similarly, we observe gain of transcriptional activity ( $>2.8$-fold) of both $\mathrm{LEF} / \mathrm{TCF} / \beta$-catenin and NF- $\kappa \mathrm{B}$ in PPP2CA-silenced LNCaP cells, when compared with non-targeted siRNA-expressing cells (LNCaP-NT) (Figure 3A). In accordance with these findings, our immunoblot analysis reveal decreased nuclear accumulation of $\beta$-catenin and NF- $\kappa \mathrm{B}$ that correlate with their increased cytoplasmic levels in high PPP2CA-expressing (PC3-PPP2CA and LNCaP-NT) cells as compared with their low PPP2CAexpressing sublines (PC3-Neo and LNCaP-shPPP2CA) (Figure $3 \mathrm{~B}$ ). These findings are further confirmed in immunofluorescence assay. The data show that $\beta$-catenin is predominantly localised in the membrane region in PPP2CA-overexpressing LNCaP (endogenous) and PC3-PPP2CA (exogenous) cells, whereas its nuclear staining is prominent in $P P P 2 C A$-silenced LNCaP or low endogenous PPP2CA-expressing PC3 cells. Similarly, we observe reduced nuclear localisation of $\mathrm{NF}-\kappa \mathrm{B}$ in PPP2CA-overexpressing LNCaP-NT and PC3-PPP2CA cells as compared with low PPP2CA-expressing (PC3-Neo and LNCaPshPPP2CA) cells (Figure 3C).

We next investigated the involvement of $\beta$-catenin and NF- $\kappa \mathrm{B}$ in PPP2CA-induced EMT reversal and suppression of migration and invasion. For this, we transfected PPP2CA-overexpressing PC3 cells with constitutively active mutants of $\beta$-catenin $(\beta$-catenin-S33Y) and/or IKK $\beta$ (IKK $\beta$-SSEE) along with their respective control vectors (pcDNA3 and pCMV6). Our data show that transfection of active $\beta$-catenin and IKK $\beta$ mutants efficiently restores the $\beta$-catenin and NF- $\kappa \mathrm{B}$ transcriptional activity, respectively, in $\mathrm{PC} 3-\mathrm{PPP} 2 \mathrm{CA}$ cells, while it remains suppressed in control-transfected cells as observed in promoter-reporter assay (Figure 3D). This is accompanied by enhanced nuclear 
accumulation of $\beta$-catenin and NF- $\kappa \mathrm{B}$ in active mutant-transfected PC3-PPP2CA cells (Figure 3E, upper panel). Interestingly, we also observe that activation of either $\beta$-catenin or NF- $\kappa \mathrm{B}$ led to partial loss of epithelial (E-cadherin) and regain of mesenchymal (Twist) markers, while their simultaneous activation reverse PPP2CAinduced EMT completely (Figure 3E, lower panel). In addition, migration and invasive potential of PC3-PPP2CA cells is also restored upon forced activation of $\beta$-catenin and NF- $\kappa \mathrm{B}$ (Figure $3 \mathrm{~F}$ ). Together, these findings indicate that both $\beta$-catenin and NF- $\kappa \mathrm{B}$ cooperatively mediate PPP2CA loss-induced EMT and invasiveness of PCa cells.

Akt mediates PPP2CA silencing-induced activation of $\beta$-catenin and NF- $\kappa$ B. Having observed important roles of $\beta$-catenin and
NF- $\kappa \mathrm{B}$ in mediating the effect of PPP2CA downregulation, we next investigated the mechanism(s) underlying their suppression in PPP2CA-overexpressing PCa cells. As Akt is a target of PP2A and its downstream signalling has been shown to promote EMT and aggressive tumour phenotype (Grille et al, 2003; Bhardwaj et al, 2011; Yoo et al, 2011), we examined if its activation is involved in mediating enhanced transcriptional activity of $\beta$-catenin and NF- $\kappa \mathrm{B}$ upon PPP2CA silencing. For this, PPP2CA-silenced LNCaP were treated with pharmacological inhibitors of Akt (LY294002) and their effect on transcriptional activity of $\beta$-catenin and NF- $\kappa \mathrm{B}$ was examined. The data reveal that Akt inhibition leads to abrogation of $P P P 2 C A$ silencing-induced stimulation of transcriptional activity of $\beta$-catenin and NF- $\kappa \mathrm{B}$ (Figure $4 \mathrm{~A}$, left panel). We later confirmed this finding by transfecting the PC3-PPP2CA cells
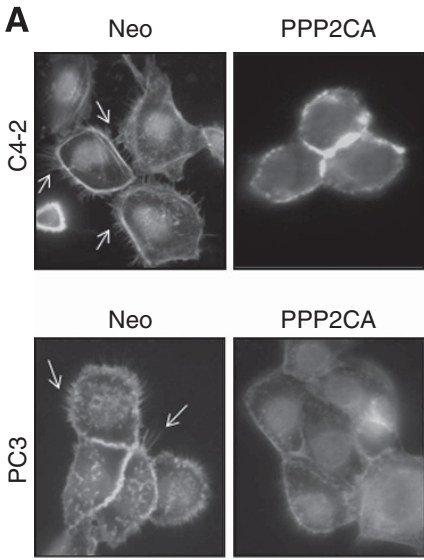

PPP2CA

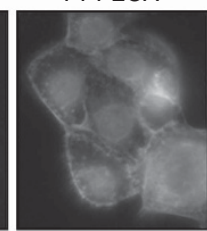

NT

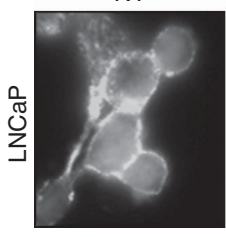

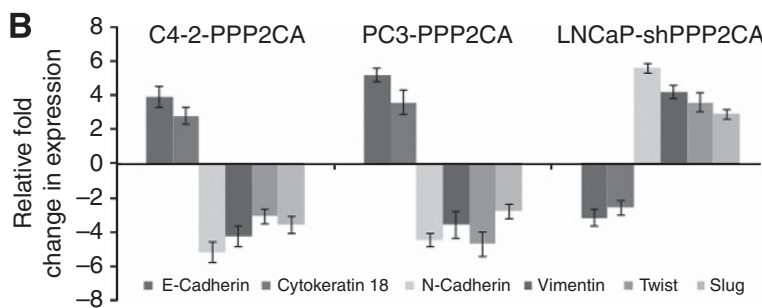

C

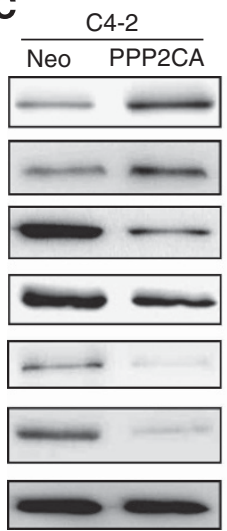

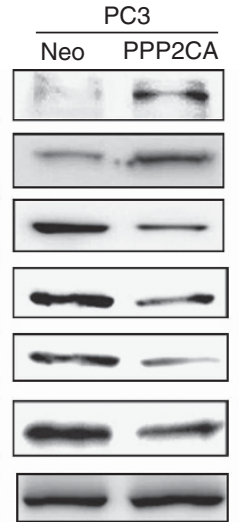

LNCaP

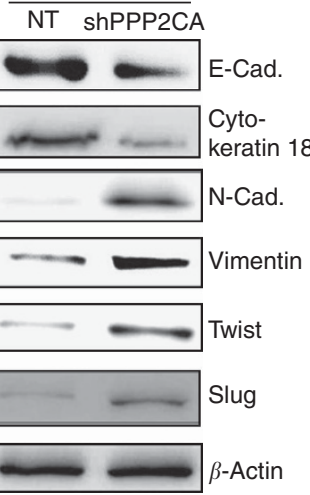

Figure 2. PPP2CA overexpression causes reversal of EMT in PCa cells. (A) PPP2CA-overexpressing or PPP2CA-silenced PCa cells were grown on fluorodish, fixed and stained with Alexa Fluor 488-conjugated phalloidin. Images were taken under confocal microscope. Data show that low PPP2CA-expressing (C4-2-Neo and PC3-Neo and LNCaP-shPPP2CA) cells exhibited several filopodia- and lamellipodia-like projections (arrows) as compared with PPP2CA-overexpressing (PC3-PPP2CA and C4-2-PPP2CA and LNCaP-NT) cells. Expression of various epithelial (E-cadherin and cytokeratin-18) and mesenchymal (N-cadherin, vimentin, Slug and Twist) markers at (B) transcript and (C) protein levels was examined by qRT-PCR and immunoblot assays, respectively. Data are presented as fold change in expression upon PPP2CA overexpression and silencing. Bars represent mean \pm s.d., $n=3$.

Figure 3. Suppression of $\beta$-catenin and NF- $\kappa$ B is responsible for PPP2CA-mediated reversal of EMT and reduced aggressiveness.

(A) Transcriptional activities of $\beta$-catenin/LEF/TCF and NF- $\kappa$ B in PPP2CA-overexpressing or PPP2CA-silenced PCa cells were measured as described in Materials and Methods section. Data are presented as fold change in normalised luciferase activity. (B) Expression level of $\beta$-catenin and NF- $\kappa \mathrm{B}$ in different cellular fractions was examined by immunoblot analysis. Laminin, $\alpha$-tubulin and $\beta$-actin were used as loading controls for nuclear, cytoplasmic and total protein, respectively. (C) Cells grown on glass bottom were fixed, incubated with $\beta$-catenin or NF- $\kappa$ B antibodies for $90 \mathrm{~min}$ at room temperature and subsequently stained using FITC-conjugated (for $\beta$-catenin) or TRITC-conjugated (for NF- $\kappa$ B) goat anti-rabbit secondary antibodies for $60 \mathrm{~min}$. Thereafter, cells were washed, mounted and observed under confocal fluorescent microscope. (D) PC3-PPP2CA cells were grown in six-well plate and transiently transfected with constitutively active $\beta$-catenin ( $\beta$-catenin-S33Y) and IKK $\beta$ (IKK $\beta$-SSEE) mutants (to activate $\beta$-catenin and NF- $\kappa \mathrm{B}$, respectively) along with controls vectors. At $24 \mathrm{~h}$ post-transfection, cells were again transfected with TOPflash/ FOPflash and NF- $\kappa$ B luciferase promoter-reporter constructs to examine LEF/TCF and NF- $\kappa$ B activity as described previously. (E) PC3-PPP2CA cells were transfected with constitutively active $\beta$-catenin and IKK $\beta$ mutants or their respective control plasmids. Thereafter, nuclear (Nuc) and total protein lysates were prepared after 24 and $48 \mathrm{~h}$ of transfection and expression level of $\beta$-catenin and NF- $\kappa \mathrm{B}$ (after $24 \mathrm{~h}$ in nuclear lysate) and E-cadherin and Twist (after $48 \mathrm{~h}$ in total lysate) were examined by immunoblot analysis. Laminin (for nuclear fraction) and $\beta$-actin (for total protein) were used as loading controls. (F) Cells were transiently transfected with constitutive active $\beta$-catenin and IKK $\beta$ mutants, trypsinised after $48 \mathrm{~h}$, and re-seeded at equal density in transwell chambers (uncoated or Matrigel-coated). Numbers of migrated/invaded cells were counted in random fields following fixation and staining. Bars represent mean \pm s.d. $(n=3)$; ${ }^{*}<0.05$ and ${ }^{\star *} P<0.01$. 
with constitutively active protein kinase B/Akt mutant or its vector only control. The data show that inhibitory effect of PPP2CA overexpression on transcriptional activity of $\mathrm{TCF} / \mathrm{LEF} / \beta$-catenin and NF- $\kappa \mathrm{B}$ is diminished after re-activation of Akt in PC3PPP2CA cells (Figure 4A, right panel). Accordingly, we observe an enhanced nuclear localisation of both $\beta$-catenin and NF- $\kappa \mathrm{B}$ in PC3-PPP2CA cells upon Akt activation, whereas the opposite is observed upon Akt inhibition in LNCaP-shPPP2CA cells (Figure $4 \mathrm{~B}$, upper panel). In additional assays, we find an inverse association of PPP2CA expression with Gsk3- $\beta$ and $\mathrm{I} \kappa \mathrm{B}-\alpha$
A
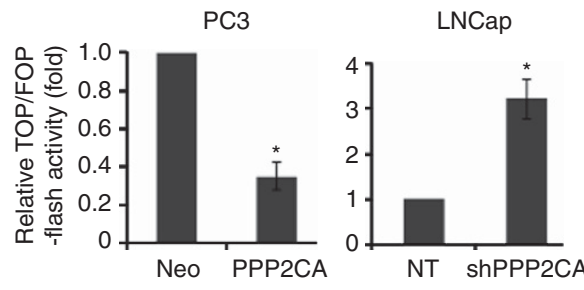

B
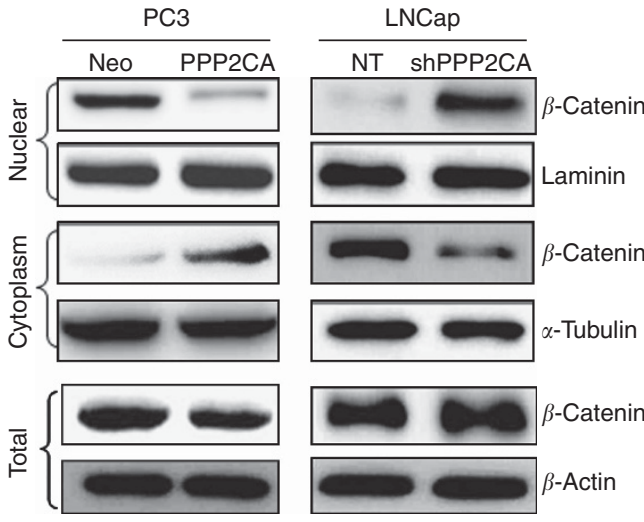

C
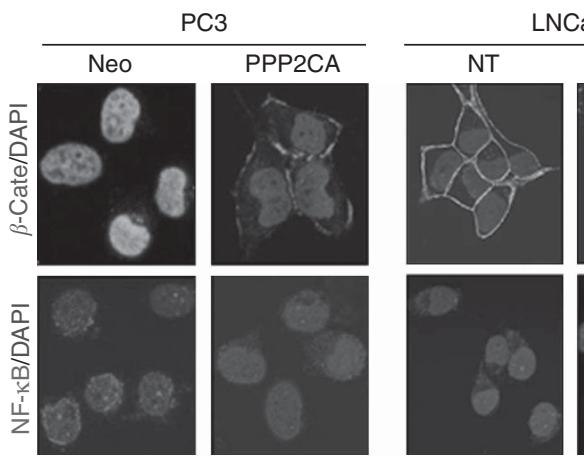

NCap

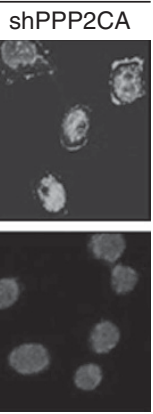

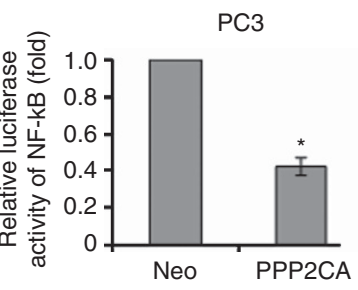
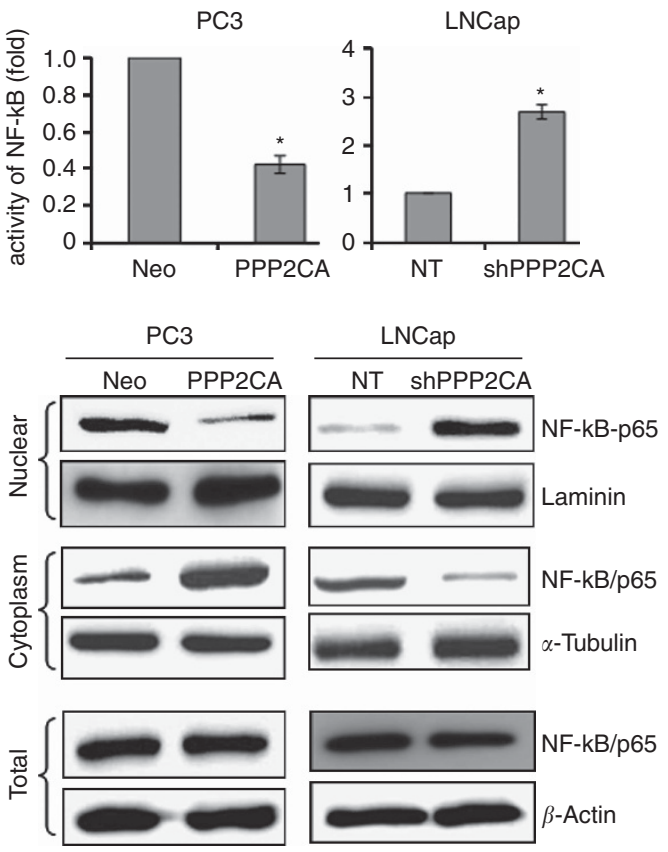

D

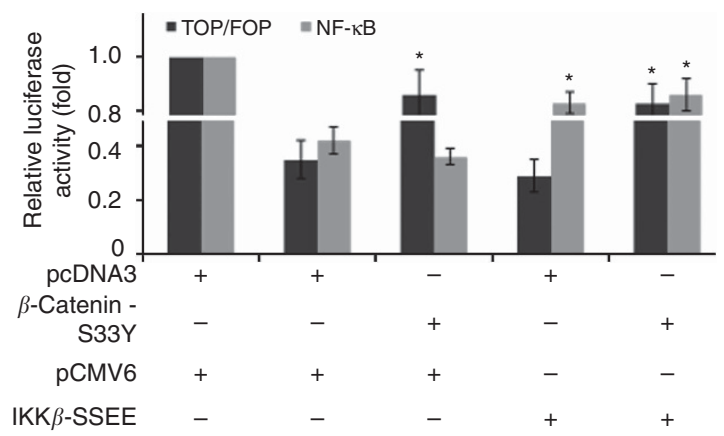

F

Migration
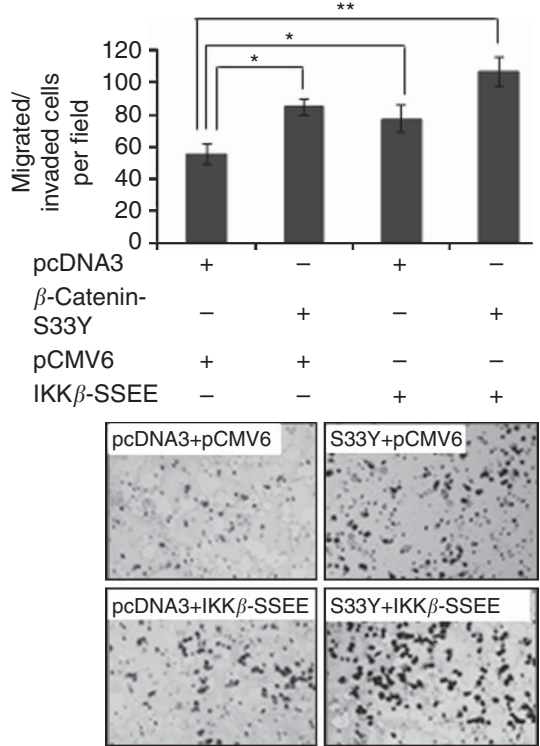

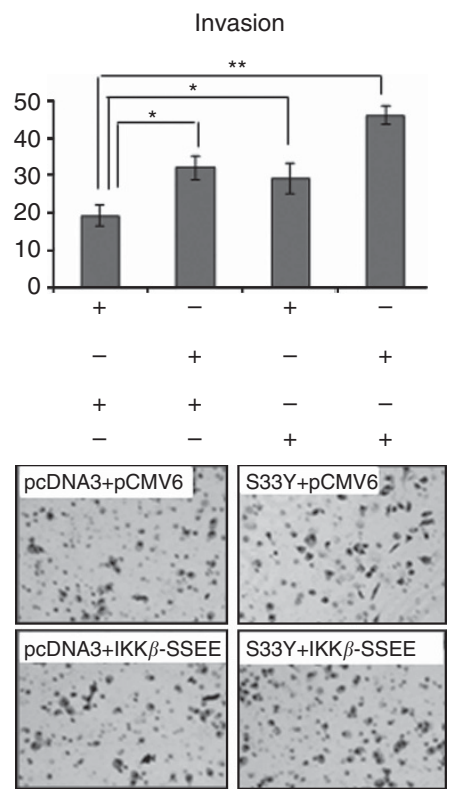


phosphorylation in PCa cells (Figure 4B, lower panel). Although Gsk3- $\beta$ phosphorylation leads to its inactivation, phosphorylation of $\mathrm{I} \kappa \mathrm{B}-\alpha$ is associated with its destabilisation as observed in our data (Figure $4 \mathrm{~B}$, lower panel). Together, these findings suggest a role of PP2A/Akt axis in regulation of $\beta$-catenin and NF- $\kappa \mathrm{B}$ in PCa cells.

Restored PPP2CA expression suppresses prostate tumour growth and metastasis. To examine the effect of PPP2CA restoration on tumourigenicity and metastatic potential of $\mathrm{PCa}$ cells, control (PC3-Neo) and PPP2CA-overexpressing PC3 cells (PC3-PPP2CA) were injected into the dorsal prostatic lobe of immunodeficient male mice (4 to 6-week old). Tumour growth was monitored by palpation and mice were killed 30 days post-injection. We observed $100 \%$ tumour incidence in both the control and PC3-PPP2CA injected mice; however, tumours in the latter group were significantly smaller. Average volume and weight of tumours in PC3-PPP2CA group were $317.1 \mathrm{~mm}^{3}$ (range from 171.5 to $490.8 \mathrm{~mm}^{3}$ ) and $0.31 \mathrm{~g}$ (range from 0.13 to $0.46 \mathrm{~g}$ ), respectively, as compared with $1803.98 \mathrm{~mm}^{3}$ (range from 1369.9 to $2254.0 \mathrm{~mm}^{3}$ ) and $1.56 \mathrm{~g}$ (range from 1.1 to $2.11 \mathrm{~g}$ ) in PC3-Neo group (Figures 5A and B). Immunohistochemical analyses on paraffin-embedded tumour sections revealed significant decrease $(>40 \% ; P<0.01)$ in Ki67-positive cells, whereas a greater percentage of TUNEL-positive cells ( $>50 \%$; $P<0.01)$ was observed in tumours generated from PC3-PPP2CA cells as compared with those developed from PC3-Neo cells (Figures 5C and D).

In parallel, we also examined the effect of $P P P 2 C A$ restoration on PCa metastasis. Tissues from suspected sites of metastasis (liver, lungs and lumber lymph nodes) were collected from tumourbearing mice and fixed in Bouin's solution, and visible metastatic nodules were quantified. Data demonstrate high metastases in case of PC3-Neo mice as evident from the presence of multiple metastatic nodules in lungs and livers (Figure 6A). Furthermore, all of the tumour-bearing mice from PC3-Neo group carried enlarged lumber lymph nodes and exhibited significant differences in average weight (Figure 6A). To further confirm the presence of tumour cells in the suspected lesions, we sectioned the tissue following paraffin embedding and stained with H\&E. Microscopic examination revealed the presence of tumour cell nests in stained tissue sections from PC3-Neo group as depicted in representative photomicrographs (Figure 6B). Furthermore, bone (femur) specimens from the mice were also collected, decalcified and examined for metastasis. No visible metastatic characteristics were observed in any of the bone from PC3-Neo and PC3-PPP2CA group (data not shown). Interestingly, when we examined H\&E-stained tissue sections, we found presence of micro-metastatic colonies in PC3Neo group, whereas no metastatic colonies were observed in bone specimens collected from PC3-PPP2CA group (Figure 6B, lower panel). Altogether, our data provide strong evidence for the role of PPP2CA downregulation in the progression and metastasis of PCa cells.
A

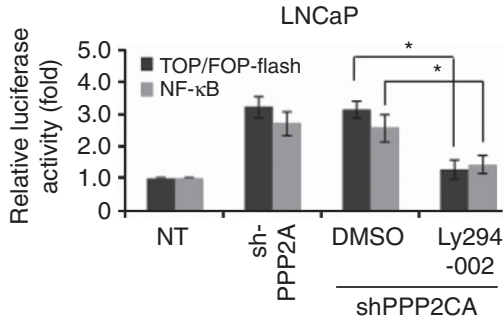

B
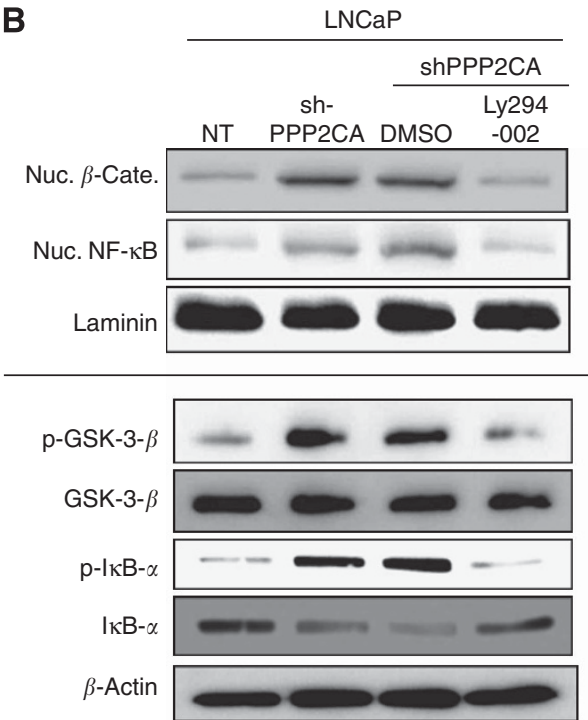

PC3
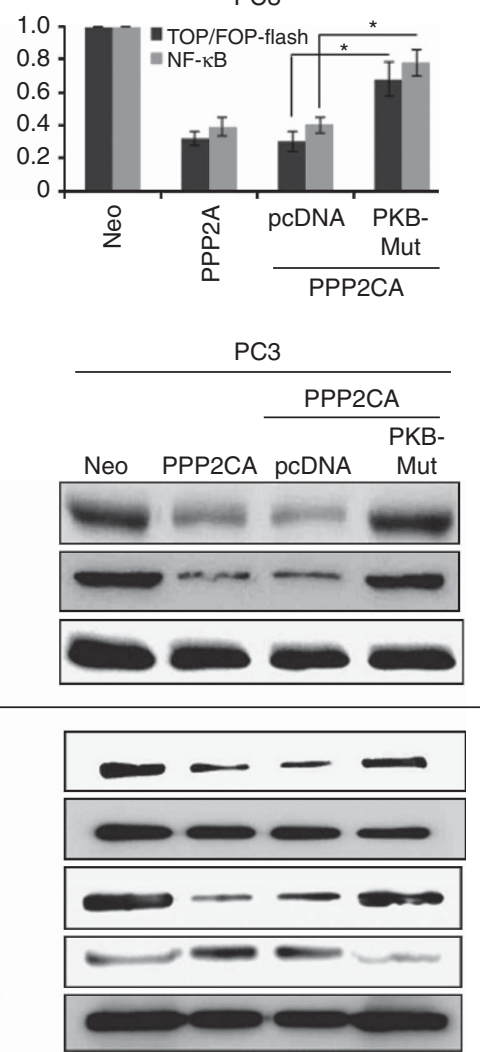

Figure 4. Role of Akt in PPP2CA overexpression-mediated suppression of $\beta$-catenin and NF- $k$ B. (A) PC3-PPP2CA cells were transiently transfected with constitutively active PKB mutant or control plasmid for $24 \mathrm{~h}$, and LNCaP-shPPP2CA cells were pre-treated (for $1 \mathrm{~h}$ ) with PI3K/Akt inhibitor (LY294002). Subsequently, cells were co-transfected with TOPflash/FOPflash/NF- $\kappa$ B luciferase promoter-reporter constructs along with control plasmids for $24 \mathrm{~h}$ and luciferase activities were measured. Bars represents mean \pm s.d. $(n=3)$, $* P<0.01$. (B) Following transfection with active PKB mutant or PI3K inhibitor treatment, nuclear and total proteins were prepared and effect on localisation of $\beta$-catenin and NF- $\kappa$ B (in nuclear protein; upper panel) and on $\mathrm{p}-\mathrm{Gsk} 3-\beta / \mathrm{Gsk} 3-\beta$ and $\mathrm{p}-\mathrm{l}_{\kappa \mathrm{B}}-\alpha / \mathrm{l}_{\kappa} \mathrm{B}-\alpha$ (in total protein; lower panel) was examined by immunoblot analysis. Laminin (for nuclear protein) and $\beta$-actin (for total protein) were used as loading controls. 


\section{DISCUSSION}

Several recent observations, including ours, have suggested an important role of $\mathrm{PP} 2 \mathrm{~A}$ in $\mathrm{PCa}$ progression and castrationresistance (Bhardwaj et al, 2011; Bluemn et al, 2013; Pandey et al, 2013). In the same line, this study revealed that loss of PPP2CA, a gene encoding the catalytic subunit of $\mathrm{PP} 2 \mathrm{~A}$, promotes metastatic progression of PCa cells (Figure 7). Our data from 'gain' and 'loss' of function studies, provide compelling evidence for a role of PPP2CA in malignant behaviour of prostate tumour cells by modulating EMT process. Mechanistic studies reveal the involvement of Akt-mediated activation of $\beta$-catenin and NF- $\kappa \mathrm{B}$ in PPP2CA loss-induced EMT and potentiation of PCa cell migration and invasion. Finally, our data from in vivo studies establish a direct inverse association of PPP2CA expression with prostate tumour growth and metastasis.

Metastasis is a complex and multistep phenomena, which initiates and progresses as a result of several molecular alterations (Valastyan and Weinberg, 2011). The regulatory networks that control such molecular alterations in PCa cells are, however, poorly understood. Our investigations reveal a significant role of PPP2CA in reducing aggressive phenotypes, that is, invasion and migration, of PCa cells. This is highly significant considering the fact that the castration-resistant PCa cells are also highly aggressive and more metastatic than their castration-sensitive counterparts (Jennbacken et al, 2006; Srivastava et al, 2012). Epithelial-to-mesenchymal transition is an important event that aids in invasion and subsequent metastatic dissemination of tumour cells to secondary sites (Nauseef and Henry, 2011). During EMT, tumour cells acquire the expression of mesenchymal markers such as vimentin, $\mathrm{N}$-cadherin, Twist and Slug, whereas epithelial markers, such as E-cadherin that promote cell-cell contact, are usually lost (Kang and Massague, 2004; Li et al, 2012; Srivastava et al, 2012). These molecular changes facilitate detachment of the tumour cell from the primary site and migration and invasion across the extracellular matrix (Valastyan and Weinberg, 2011). In accordance with this, we observed an increased expression of epithelial and decreased expression of mesenchymal markers in PPP2CA-overexpressing cells. A similar role of PP2A in the regulation of malignant behaviour and EMT has been reported in other cancer types as well (Ito et al, 2000; Xu and Deng, 2006). Our in vivo data show that the overexpression of $P P P 2 C A$ decreases the metastatic potential of PC3 cells to the various organs including liver, lung, lymph nodes and bone. Metastasis of PC3 cells to liver, lung and lymph nodes in orthotopic mouse model of PCa is widely reported (Rembrink et al, 1997; Wu et al, 2010). However, contradictory reports are available on the bone metastasis of PC3 cells upon intra-prostate implantation (Rembrink et al, 1997; Yang et al, 1999). Our findings are in consistence with the previous study published by Yang et al (1999), in which they observed skeletal metastases (skull, rib, pelvis, femur and tibia) of intra-prostate implanted PC3 cells.

Prostatic epithelial cells undergo EMT in response to the abnormal activation of several signalling pathways (Nauseef and Henry, 2011). Aberrant activation of Wnt $/ \beta$-catenin and NF- $\kappa \mathrm{B}$ has been linked with the high-grade PCa (Ross et al, 2004; Jaggi et al, 2005; Lessard et al, 2006). Moreover, multiple reports document the involvement of $\mathrm{Wnt} / \beta$-catenin as well as NF- $\kappa \mathrm{B}$ in the regulation of EMT and aggressive phenotypes of various tumour cells (Ganesan et al, 2008; Pantuck et al, 2010; Wu et al, 2012; Li et al, 2012, 2013). In these contexts, we investigated the involvement of $\beta$-catenin and NF- $\kappa \mathrm{B}$ in the PPP2CA-mediated regulation of EMT and aggressive phenotype of $\mathrm{PCa}$ cells. The data demonstrate that activation status of both $\beta$-catenin and NF- $\kappa \mathrm{B}$ is inversely correlated with the expression of PPP2CA. In general, activation of the Wnt pathway is associated with the nuclear accumulation of $\beta$-catenin, which then enhanced the transcriptional activity of LEF/TCF-responsive promoter through complex formation (Moon et al, 2004; Kypta and Waxman, 2012). A complex set of factors including GSK-3 $\beta$ are involved in this signalling process. GSK-3 $\beta$ acts as an inhibitor of $\beta$-catenin by inducing its phosphorylation-mediated proteolytic degradation (Moon et al, 2004; Kypta and Waxman, 2012). Similarly,
A

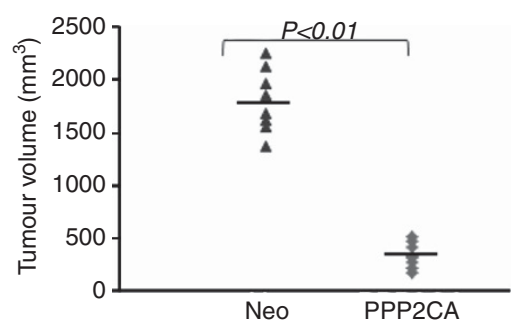

C
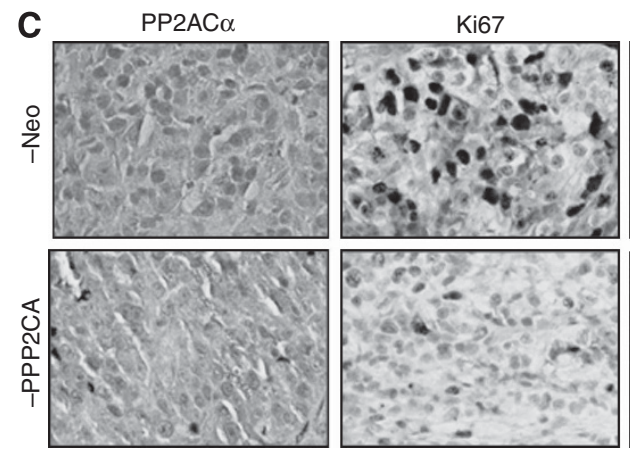

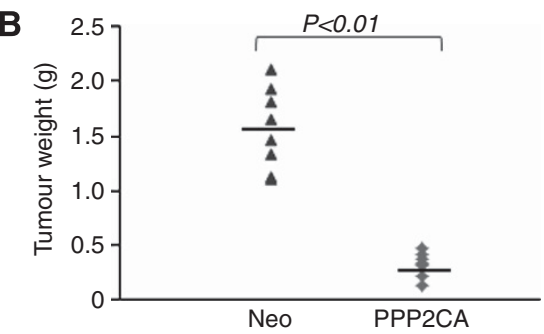

TUNEL

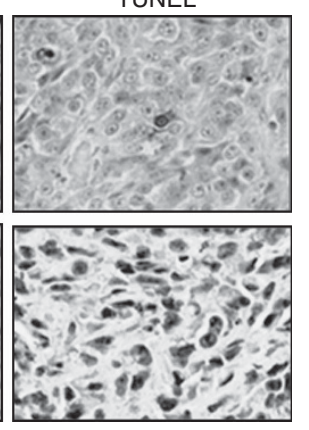

D

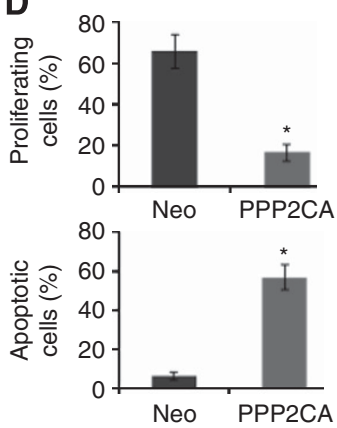

Figure 5. PPP2CA overexpression decreases tumourigenicity of PCa cells in orthotopic mice model. PC3 (control and PPP2CA-overexpressing) cells were injected into the prostate of mice ( $n=8$ per group) and killed after 30 days. (A) Volume and (B) weight of the tumours from the each animal of the control and PPP2CA-overexpressing group were calculated. Dark line indicates the median value of the respective group. (C) Immunohistological analysis of paraffin-embedded prostate tumours for PP2Ac $\alpha$ expression (left panel), Ki67 expression (a proliferative marker; middle panel) and TUNNEL assay (right panel). (D). Number of proliferating (upper panel) and apoptotic (lower panel) cells were counted in 10 random view fields (magnification $\times 100$ ) in a double-blinded manner and expressed as mean \pm s.d., $n=3$, per field view. ${ }^{\star} P<0.01$. 
A
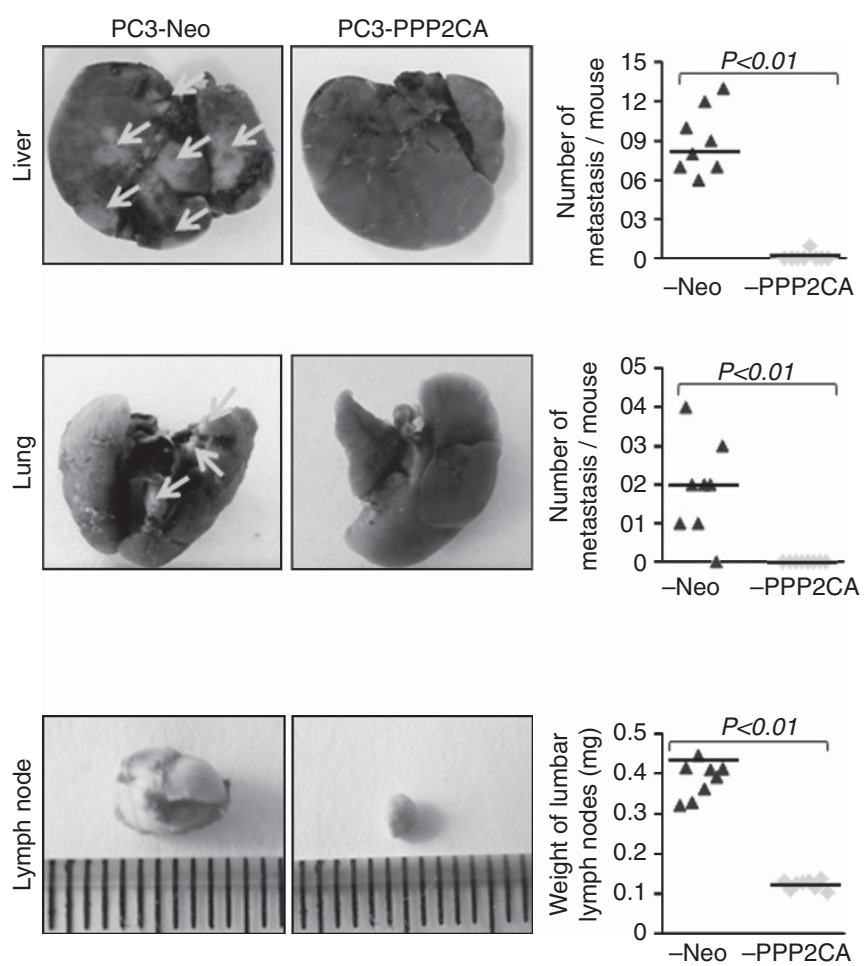

B
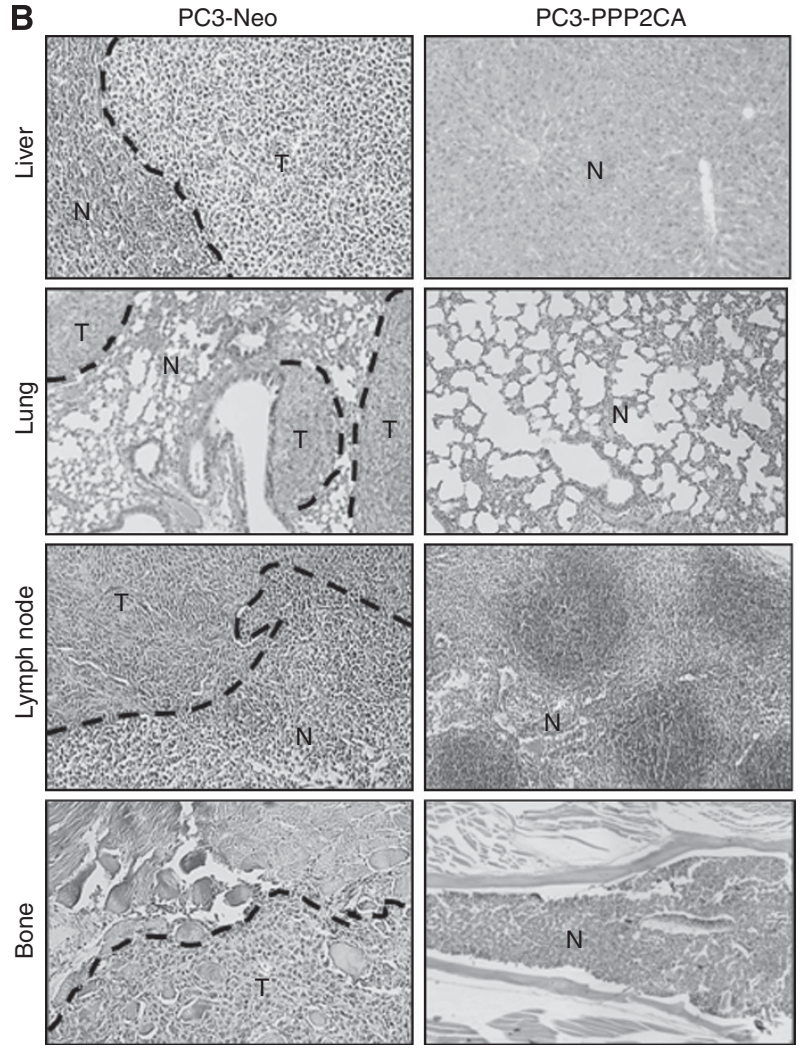

Figure 6. PPP2CA restoration decreases incidence of metastasis. (A) Liver (upper), lungs (middle) and lumber lymph nodes (lower) from mice were excised out and fixed in Bouin's solution and number of metastatic colonies were counted (in case of liver and lungs) and total mass of all the lumber lymph nodes was taken. Data presented as number of metastatic modules per mouse in case of liver and lungs and, total weight of the lumber lymph nodes per mouse. Dark line indicates the median value of the group. (B) Haematoxylin and eosin staining of liver, lung, lymph node and bone sections from control and PPP2CA-overexpressing group. Mice group injected with PC3-Neo cells show metastatic deposits of cancer cells in liver, lung, lymph node and bone, whereas PPP2CA-overexpressing group had no gross evidence of deposits of cancer cells.

Abbreviations: $\mathrm{N}=$ normal; $\mathrm{T}=$ tumour.

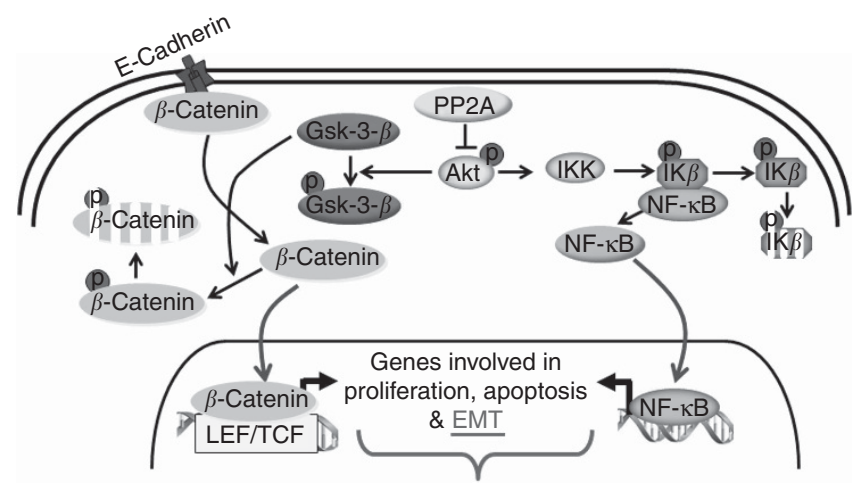

Metastatic progression of prostate cancer

Figure 7. Diagrammatic representation of molecular pathways targeted by PP2A to suppress metastatic progression of PCa. Restoration of PP2A activity inhibits Akt phosphorylation, which then suppresses $\beta$-catenin and NF- $\kappa$ B through activation of GSK3 $\beta$ and inhibition of IKK, respectively. Inactivation of $\beta$-catenin and NF- $\kappa \mathrm{B}$ leads to reversal of EMT and attenuation of tumour cell aggressiveness.

inactivation of GSK-3 $\beta$ leads to stabilisation of $\beta$-catenin, which subsequently enters the nucleus and promotes the expression of EMT-associated genes (Moon et al, 2004). On the other hand, activation of $\operatorname{IKK} \beta$ leads to phosphorylation of $\operatorname{Ik} \beta-\alpha$, a protein that keeps NK- $\kappa \mathrm{B}$ sequestered in the cytoplasm (Gilmore, 2006). Phosphorylation of $\operatorname{Ik} \beta-\alpha$ induces its degradation and release of
$\mathrm{NF}-\kappa \mathrm{B}$, which then translocates into the nucleus to induce gene expression (Gilmore, 2006). Our data using active $\beta$-catenin and IKK $\beta$ mutants provide convincing evidence to suggest the participation of both $\beta$-catenin and NF- $\kappa \mathrm{B}$ in PPP2CA-mediated regulation of EMT and malignant properties in PCa cells.

Accumulating evidence suggests that PP2A can regulate multiple signalling pathways involved in cancer pathogenesis (Janssens and Goris, 2001; Perrotti and Neviani, 2013). In an earlier study, we also demonstrated that downmodulation of PP2A led to the activation of Akt and ERK, which sustained the growth of prostate tumour cells in androgen-depleted media (Bhardwaj et al, 2011). These signalling nodes were also involved in partial activation of androgen receptor signalling in a ligand-independent manner (Bhardwaj et al, 2011). In this study, our data reveal a role of PP2A in negative regulation of $\beta$-catenin and NF- $\kappa \mathrm{B}$ through Akt inactivation. Akt-mediated regulation of NF- $\kappa \mathrm{B}$ through IKK has been shown by others as well (Dan et al, 2008). Furthermore, a recent report suggested that carnosic acid induced growth inhibition in PCa cells involved PP2A-mediated suppression of Akt/IKK/NF- $\kappa \mathrm{B}$ pro-survival signalling (Kar et al, 2012). In additional studies, PP2A has been shown to regulate the activity of $\beta$-catenin. Seeling et al (1999) reported that the regulatory subunit of PP2A (PP2A-B) interfered with the formation of APC/Axin/ Gsk3 $\beta$ complex, an inhibitory complex of $\beta$-catenin, and thus regulated the stabilisation and nuclear translocation of $\beta$-catenin (Seeling et al, 1999). In addition, based on the study performed in Drosophila, it was proposed that PP2A55 $\alpha$ subunit of PP2A directly interacts with $\beta$-catenin and subsequently promotes its phosphorylation and degradation (Zhang et al, 2009). Findings 
from our work suggest that PP2A-mediated $\beta$-catenin suppression in PCa cells is mediated through GSK-3 $\beta$, which remains activated because of suppressive effect of PP2A on Akt. Similarly, Akt-mediated activation of NF- $\kappa \mathrm{B}$ through IKK is also lost, when PPP2CA expression is restored in PCa cells. These findings are suggestive of a context-dependent impact of PP2A on signalling networks, which may underlie its functional diversity in biological processes.

In summary, our findings have provided compelling support for a tumour-suppressive role of PP2A in PCa and suggest that it likely serves as a mechanistic link between castration-resistance and aggressive tumour phenotypes. In light of other recent observations, it appears that dysregulation of PP2A through altered expression of its catalytic or regulatory subunits may be a common phenomenon in advanced PCa. On these bases, it can be suggested that PP2A signalling is a key regulator of PCa progression and metastasis and its targeting may be useful in preventing the disease progression and/or treatment of the disease that has already advanced.

\section{ACKNOWLEDGEMENTS}

We acknowledge the funding support from Department of Defense (PC080496, PC110545), NIH/NCI (CA175772) and USAMCI.

\section{CONFLICT OF INTEREST}

The authors declare no conflict of interest.

\section{REFERENCES}

Arora S, Bhardwaj A, Srivastava SK, Singh S, McClellan S, Wang B, Singh AP (2011) Honokiol arrests cell cycle, induces apoptosis, and potentiates the cytotoxic effect of gemcitabine in human pancreatic cancer cells. PLoS One 6(6): e21573.

Bhardwaj A, Singh S, Srivastava SK, Honkanen RE, Reed E, Singh AP (2011) Modulation of protein phosphatase $2 \mathrm{~A}$ activity alters androgenindependent growth of prostate cancer cells: therapeutic implications. Mol Cancer Ther 10(5): 720-731.

Bluemn EG, Spencer ES, Mecham B, Gordon RR, Coleman I, Lewinshtein D, Mostaghel E, Zhang X, Annis J, Grandori C, Porter C, Nelson PS (2013) PPP2R2C loss promotes castration-resistance and is associated with increased prostate cancer-specific mortality. Mol Cancer Res 11(6): 568-578.

Cooperberg MR, Moul JW, Carroll PR (2005) The changing face of prostate cancer. J Clin Oncol 23(32): 8146-8151.

Dan HC, Cooper MJ, Cogswell PC, Duncan JA, Ting JP, Baldwin AS (2008) Akt-dependent regulation of NF- $\{$ kappa $\}$ B is controlled by mTOR and Raptor in association with IKK. Genes Dev 22(11): 1490-1500.

Feldman BJ, Feldman D (2001) The development of androgen-independent prostate cancer. Nat Rev Cancer 1(1): 34-45.

Ganesan K, Ivanova T, Wu Y, Rajasegaran V, Wu J, Lee MH, Yu K, Rha SY, Chung HC, Ylstra B, Meijer G, Lian KO, Grabsch H, Tan P (2008) Inhibition of gastric cancer invasion and metastasis by PLA2G2A, a novel beta-catenin/TCF target gene. Cancer Res 68(11): 4277-4286.

Gilmore TD (2006) Introduction to NF-kappaB: players, pathways, perspectives. Oncogene 25(51): 6680-6684.

Grille SJ, Bellacosa A, Upson J, Klein-Szanto AJ, van RF, Lee-Kwon W, Donowitz M, Tsichlis PN, Larue L (2003) The protein kinase Akt induces epithelial mesenchymal transition and promotes enhanced motility and invasiveness of squamous cell carcinoma lines. Cancer Res 63(9): 2172-2178.

Ito A, Kataoka TR, Watanabe M, Nishiyama K, Mazaki Y, Sabe H, Kitamura Y, Nojima H (2000) A truncated isoform of the PP2A B56 subunit promotes cell motility through paxillin phosphorylation. EMBO J 19(4): 562-571.
Jaggi M, Johansson SL, Baker JJ, Smith LM, Galich A, Balaji KC (2005) Aberrant expression of E-cadherin and beta-catenin in human prostate cancer. Urol Oncol 23(6): 402-406.

Janssens V, Goris J (2001) Protein phosphatase 2A: a highly regulated family of serine/threonine phosphatases implicated in cell growth and signalling. Biochem J 353(Pt 3): 417-439.

Jennbacken K, Gustavsson H, Welen K, Vallbo C, Damber JE (2006) Prostate cancer progression into androgen independency is associated with alterations in cell adhesion and invasivity. Prostate 66(15): 1631-1640.

Joly F, Tannock IF (2004) Chemotherapy for patients with hormonerefractory prostate cancer. Ann Oncol 15(11): 1582-1584.

Kang Y, Massague J (2004) Epithelial-mesenchymal transitions: twist in development and metastasis. Cell 118(3): 277-279.

Kar S, Palit S, Ball WB, Das PK (2012) Carnosic acid modulates Akt/IKK/ NF-kappaB signaling by PP2A and induces intrinsic and extrinsic pathway mediated apoptosis in human prostate carcinoma PC-3 cells. Apoptosis 17(7): 735-747.

Kypta RM, Waxman J (2012) Wnt/beta-catenin signalling in prostate cancer. Nat Rev Urol 9: 418-428.

Lessard L, Karakiewicz PI, Bellon-Gagnon P, Alam-Fahmy M, Ismail HA, Mes-Masson AM, Saad F (2006) Nuclear localization of nuclear factor-kappaB p65 in primary prostate tumors is highly predictive of pelvic lymph node metastases. Clin Cancer Res 12(19): 5741-5745.

Li CW, Xia W, Huo L, Lim SO, Wu Y, Hsu JL, Chao CH, Yamaguchi H, Yang NK, Ding Q, Wang Y, Lai YJ, LaBaff AM, Wu TJ, Lin BR, Yang MH, Hortobagyi GN, Hung MC (2012) Epithelial-mesenchymal transition induced by TNF-alpha requires NF-kappaB-mediated transcriptional upregulation of Twist1. Cancer Res 72(5): 1290-1300.

Li X, Xu Y, Chen Y, Chen S, Jia X, Sun T, Liu Y, Li X, Xiang R, Li N (2013) SOX2 promotes tumor metastasis by stimulating epithelial-tomesenchymal transition via regulation of WNT/beta-catenin signal network. Cancer Lett 19 336(2): 379-389.

Min C, Eddy SF, Sherr DH, Sonenshein GE (2008) NF-kappaB and epithelial to mesenchymal transition of cancer. J Cell Biochem 104(3): 733-744.

Moon RT, Kohn AD, De Ferrari GV, Kaykas A (2004) WNT and beta-catenin signalling: diseases and therapies. Nat Rev Genet 5(9): 691-701.

Mumby M (2007) PP2A: unveiling a reluctant tumor suppressor. Cell 130(1): 21-24.

Nauseef JT, Henry MD (2011) Epithelial-to-mesenchymal transition in prostate cancer: paradigm or puzzle? Nat Rev Urol 8(8): 428-439.

Pandey P, Seshacharyulu P, Das S, Rachagani S, Ponnusamy MP, Yan Y, Johansson SL, Datta K, Fong LM, Batra SK (2013) Impaired expression of protein phosphatase $2 \mathrm{~A}$ subunits enhances metastatic potential of human prostate cancer cells through activation of AKT pathway. $\mathrm{Br} J$ Cancer 108(12): 2590-2600.

Pantuck AJ, An J, Liu H, Rettig MB (2010) NF-kappaB-dependent plasticity of the epithelial to mesenchymal transition induced by Von Hippel-Lindau inactivation in renal cell carcinomas. Cancer Res 70(2): 752-761.

Perrotti D, Neviani P (2013) Protein phosphatase 2A: a target for anticancer therapy. Lancet Oncol 14(6): e229-e238.

Prowatke I, Devens F, Benner A, Grone EF, Mertens D, Grone HJ, Lichter P, Joos S (2007) Expression analysis of imbalanced genes in prostate carcinoma using tissue microarrays. Br J Cancer 96(1): 82-88.

Rembrink K, Romijn JC, van der Kwast TH, Rubben H, Schroder FH (1997) Orthotopic implantation of human prostate cancer cell lines: a clinically relevant animal model for metastatic prostate cancer. Prostate 31(3): $168-174$.

Ross JS, Kallakury BV, Sheehan CE, Fisher HA, Kaufman Jr RP, Kaur P, Gray K, Stringer B (2004) Expression of nuclear factor-kappa B and I kappa B alpha proteins in prostatic adenocarcinomas: correlation of nuclear factor-kappa B immunoreactivity with disease recurrence. Clin Cancer Res 10(7): 2466-2472.

Seeling JM, Miller JR, Gil R, Moon RT, White R, Virshup DM (1999) Regulation of beta-catenin signaling by the B56 subunit of protein phosphatase 2A. Science 283(5410): 2089-2091.

Shankar J, Messenberg A, Chan J, Underhill TM, Foster LJ, Nabi IR (2010) Pseudopodial actin dynamics control epithelial-mesenchymal transition in metastatic cancer cells. Cancer Res 70(9): 3780-3790. 
Siegel R, Ma J, Zou Z, Jemal A (2014) Cancer statistics, 2014. CA Cancer J Clin 64(1): 9-29.

Singh AP, Bafna S, Chaudhary K, Venkatraman G, Smith L, Eudy JD, Johansson SL, Lin MF, Batra SK (2008) Genome-wide expression profiling reveals transcriptomic variation and perturbed gene networks in androgen-dependent and androgen-independent prostate cancer cells. Cancer Lett 259(1): 28-38.

Sridhar SS, Freedland SJ, Gleave ME, Higano C, Mulders P, Parker C, Sartor O, Saad F (2013) Castration-resistant prostate cancer: from new pathophysiology to new treatment. Eur Urol 65(2): 289-299.

Srivastava SK, Bhardwaj A, Singh S, Arora S, McClellan S, Grizzle WE, Reed E, Singh AP (2012) Myb overexpression overrides androgen depletioninduced cell cycle arrest and apoptosis in prostate cancer cells, and confers aggressive malignant traits: potential role in castration resistance. Carcinogenesis 33(6): 1149-1157.

Valastyan S, Weinberg RA (2011) Tumor metastasis: molecular insights and evolving paradigms. Cell 147(2): 275-292.

Wu Y, Ginther C, Kim J, Mosher N, Chung S, Slamon D, Vadgama JV (2012) Expression of Wnt 3 activates Wnt/beta-catenin pathway and promotes EMT-like phenotype in trastuzumab-resistant HER2-overexpressing breast cancer cells. Mol Cancer Res 10(12): 1597-1606.
Wu Z, Owens C, Chandra N, Popovic K, Conaway M, Theodorescu D (2010) RalBP1 is necessary for metastasis of human cancer cell lines. Neoplasia 12(12): 1003-1012.

Xu L, Deng X (2006) Suppression of cancer cell migration and invasion by protein phosphatase $2 \mathrm{~A}$ through dephosphorylation of mu- and m-calpains. J Biol Chem 281(46): 35567-35575.

Yang M, Jiang P, Sun FX, Hasegawa S, Baranov E, Chishima T, Shimada H, Moossa AR, Hoffman RM (1999) A fluorescent orthotopic bone metastasis model of human prostate cancer. Cancer Res 59(4): 781-786.

Yoo YA, Kang MH, Lee HJ, Kim BH, Park JK, Kim HK, Kim JS, Oh SC (2011) Sonic hedgehog pathway promotes metastasis and lymphangiogenesis via activation of Akt, EMT, and MMP-9 pathway in gastric cancer. Cancer Res 71(22): 7061-7070.

Zhang W, Yang J, Liu Y, Chen X, Yu T, Jia J, Liu C (2009) PR55 alpha, a regulatory subunit of PP2A, specifically regulates PP2A-mediated betacatenin dephosphorylation. J Biol Chem 284(34): 22649-22656.

This work is published under the standard license to publish agreement. After 12 months the work will become freely available and the license terms will switch to a Creative Commons AttributionNonCommercial-Share Alike 3.0 Unported License.

Supplementary Information accompanies this paper on British Journal of Cancer website (http://www.nature.com/bjc) 